\title{
Detection of Leishmania infantum kinetoplast DNA by Real Time PCR in hair of wild rabbits
}

\author{
JUAN J. AYUSO-SÁINZ1, 2 , Đ SILVIA BELINCHÓN-LORENZO², \\ JAVIER FERNÁNDEZ-COTRINA², (1) MARIBEL JIMÉNEZ³, \\ ๑ANTONIO ORDUÑA-DOMINGO ${ }^{4}$, ๑EMILIANO J. QUINTO ${ }^{1}$
}

\begin{abstract}
${ }^{1}$ Area of Nutrition and Food Science, Faculty of Medicine, University of Valladolid, Spain ${ }^{2}$ LeishmanCeres Laboratory, Parasitology Unit, Veterinary Faculty, University of Extremadura, Cáceres, Spain

${ }^{3}$ Laboratorio de Entomología Médica, Centro Nacional de Microbiología, Instituto de Salud Carlos III, Ctra. Majadahonda-Pozuelo s/n, 28220 Majadahonda, Madrid, Spain

${ }^{4}$ Servicio de Microbiología e Inmunología, Hospital Clínico Universitario de Valladolid, Valladolid, Spain
\end{abstract}

Ayuso-Sáinz J. J., Belinchón-Lorenzo S., Fernández-Cotrina J., Jiménez M., Orduña-Domingo A., Quinto E. J.

\section{Detection of Leishmania infantum kinetoplast DNA by Real Time PCR in hair of wild rabbits}

\section{Summary}

The study of potential wild mammal reservoirs is necessary for the surveillance of leishmaniosis, as Leishmania protozoans have been isolated from a wide range of wild and domestic animal species, including Leporidae. Recently, it has been demonstrated that both hares and wild rabbits can act as sylvatic reservoirs of Leishmania. In Spain, most of the research involving wild rabbits has been developed in the central area of Madrid and in the southeastern Mediterranean coast. We studied the presence of Leishmania infantum in 116 wild rabbits (Oryctolagus cuniculus) captured in Santovenia de Pisuerga, Valladolid, Spain. Hair samples were analyzed by real time PCR. L. infantum kinetoplast DNA (kDNA) was detected and quantified in 4 out of 116 analyzed animals. The estimated number of parasites obtained were quite variable, ranging from 2.60 to 276.60. Hair samples can be collected by non-invasive methods, being a proper sample for Leishmania detection in wild Leporidae, which have an important role as reservoirs of Leishmania. Our findings enhance the need for more extensive studies in different geographical areas.

Keywords: hair, Leishmania infantum, rabbit, kDNA, Real Time PCR

Leishmaniosis is a worldwide zoonoses caused by protozoan Leishmania, being Leishmania infantum the major cause of leishmaniosis in dogs and immunocompromised people in the Mediterranean area (27).

Leishmania parasites have been identified in a large number of wild animal reservoirs, where Phychodidae insects of the genus Phlebotomus and Lutzomyia act as vectors $(3,27)$. A wide range of wild mammals from different orders are adapted to infections by Leishmania spp. (4), contrary to dogs and humans $(1,26)$. Most of the wild reservoirs for all Leishmania species belong to the Rodentia order (8).

Lagomorpha order became a target due to an epidemic outbreak in Madrid (Spain) affecting about 500 immunocompetent people with both skin and visceral clinical expressions from 2009 to $2020(2,18)$. Leporidae (especially Oryctolagus cuniculus and Lepus granatensis) were the reservoirs responsible for the transmission of $L$. infantum to $P$. perniciosus pres- ent in the area $(18,20)$. Leporidae are highly adapted to Leishmania infection and do not develop a visceral form of the disease as seen in canids or humans (8). Recent studies in rabbits revealed no histological lesions typical of leishmaniosis, as well as low parasitic loads. The skin was proven as the organ with the highest parasite load, indicating its importance for both diagnosis and transmission to sand flies $(18,24)$. Xenodiagnostic studies demonstrated the ability of hares to transmit L. infantum to P. perniciosus $(18,20)$ and the detection of L. infantum in P. perniciosus from the same leishmaniosis focus in Spain $(17,14,15)$.

Serological diagnostics methods as ELISA, DFA and IFAT have been performed for the diagnosis of leishmaniosis from rabbits and hares, as well as parasitological methods such as culture and real time PCR in spleen, liver and skin $(9,11,21)$. Recently it has been demonstrated that hair samples can be used for the molecular diagnosis of both $L$. infantum and L. $m a$ - 
jor, and be employed in epidemiological, clinical, and experimental infections $(5,16,22)$. In addition, hair is easy to obtain, causing no harm to the animals, and Leishmania kDNA can remain stable inside hair over time and after extreme environmental conditions (22).

The study of wild mammal reservoirs is essential for leishmaniosis surveillance. In Spain, most of research involving wild rabbits was developed in the central area of Madrid and in the southeastern Mediterranean coast. In the area of Castille and León (North Plateau, Spain), the number of human cases were 15 from 2014 to 2018 (0.13-0.2/100.000 inhabitants) (19). Environmental changes such as disappearance of agriculture, livestock and traditional land uses, the presence of grass and shrubs, absence of predators and competitors and warmer temperatures facilitate the life and reproduction of rabbits and hares (2).

Taking these into account, the aim of this study was to determine by qPCR the presence of Leishmania kDNA in wild rabbits that could be reservoirs of the disease in an area of the province of Valladolid in Castille and León (North Plateau, 190 km northwest of Madrid), close to Santovenia de Pisuerga, a recently changed village of around 5.000 inhabitants where shrubs and grass have covered extensive areas mixed with sandy zones very auspicious for sandflies spreading.

\section{Material and methods}

Animals. A sample of 116 wild rabbits was captured between May 2017 and March 2018 in Santovenia de Pisuerga, Valladolid, Spain (ETRS89/UTM Zone 30). The sampling area was divided in 5 zones: Zone 1 (Z1: 19 animals), Z2 (28 animals), Z3 (28 animals), north ( $Z n: 22$ animals) and south (Zs: 19 animals) (Fig. 1). The sampling zones were selected due to changes in their agricultural and livestock use as well as their environmental conditions: shrubs and grass mixed with sand areas. Animals from Z1, Z2, and Z3

Spain

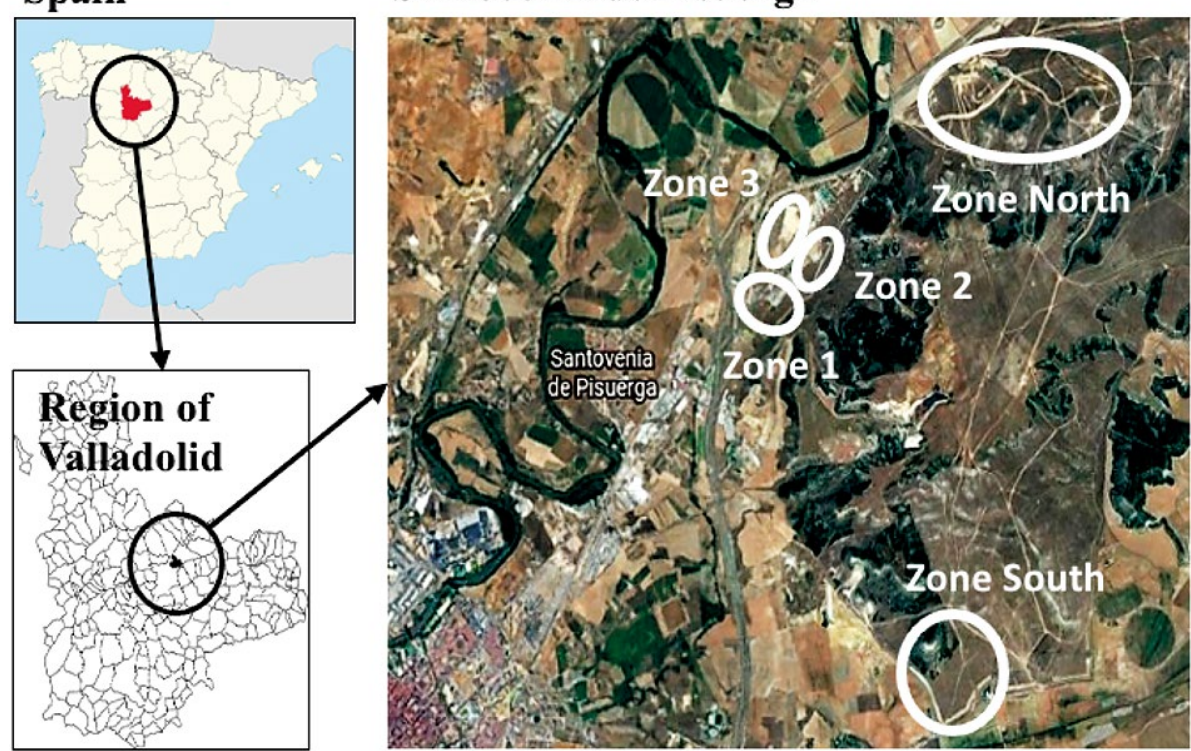

Fig. 1. Geolocation of the areas where wild rabbits were captured for Leishmania detection. Areas in Santovenia de Pisuerga, Valladolid, Castille and León, Spain could be in contact with each other; animals from $\mathrm{Zn}$ and Zs cannot be in contact neither between them nor with the other zones due to the large distances. The animals were captured by ferret hunting (10) under the authorization of the Public Health authorities of the Community of Castilla y León, sedated and euthanized following the national RD 53/2013 and the European Directive 2010/63/EU. Rabbits were transported to the lab within the first $5 \mathrm{~h}$ after their capture and were necropsied in a biological safety cabinet. Macroscopic lesions compatible with subclinical infections were not observed.

Samples. A number of 50-100 hairs were taken with scissors (avoiding wounds and/or blood spots) from two corporal zones (back and flank), introduced into sterilized plastic bags, and sent to the laboratory. Samples from all rabbits were stored at $-80^{\circ} \mathrm{C}$ until DNA extraction.

DNA extraction and qPCR analyses. About 20 hairs from each animal were introduced in screw cap sterile microtubes and incubated overnight at $56^{\circ} \mathrm{C}$ in $250 \mu \mathrm{l}$ of lysis buffer (10 mM TrisCl, 0.1 M EDTA, 0.5\% SDS) with $100 \mathrm{mg} / \mathrm{ml}$ of Proteinase K. DNA was extracted using $200 \mu \mathrm{l}$ of supernatant obtained from processed samples with the GeneJET Genomic DNA Purification Kit (ThermoFisher Scientific, Waltham, MA, USA) according to the manufacturer's instructions. The qPCR technique used in the present study was performed following previously published protocols (6). Briefly, PCR reactions were carried out in 96 wells plates in a final volume of $20 \mu 1(4 \mu 1$ of DNA $+16 \mu l$ of Reaction Mix), containing $20 \mu \mathrm{M}$ of each primer (Leish 1: 5'-AACTTTTCTGGTCCTCCGGGTAG-3' and Leish 2: 5'-ACCCCCAGTTTCCCGCC-3'), $10 \mu \mathrm{M}$ of TaqMan Probe (FAM-5'-AAAAATGGGTGCAGAAAT-3'-MGB), and the iTaq Universal Probes Supermix (Biorad Laboratories, Hercules, CA, USA). The thermal cycling profile used was one incubation step at $50^{\circ} \mathrm{C}$ for $2 \mathrm{~min}$ and an initial denaturation step at $95^{\circ} \mathrm{C}$ for $10 \mathrm{~min}$, followed by 40 cycles of denaturation at $95^{\circ} \mathrm{C}$ for $15 \mathrm{~s}$ and annealing-extension at $60^{\circ} \mathrm{C}$ for $1 \mathrm{~min}$. Each amplification run contained positive and negative controls. DNA extracted from 55.000 L. infantum promastigotes MCAN/ ES/1996/BCN150 zymodeme MON-1 was used as a positive control. DNA extracted from healthy dog blood samples was used as negative control. All analyses were performed in a Step One Plus Real Time PCR System (Applied Biosystems Laboratories, Foster City, CA, USA). To quantify Leishmania kDNA, a standard curve was carried out using DNA extracted from six quantities of L. infantum parasites (MCAN/ ES/1996/BCN150, zymodeme MON-1) ranging from 50.000 to 0.5 (dilution factor $\times 10$ ); DNA was extracted and analyzed together with the hair samples in triplicate. The threshold cycle $(\mathrm{Ct})$ corresponding to the Y-intercept of each analysis (that is, the expected $\mathrm{Ct}$ value for the estimated quantity of 1 parasite) was used as cut-off, positive being those 
samples whose $\mathrm{Ct}$ values were $\leq \mathrm{Y}$-intercept value of each assay. Samples were considered positive when the $\mathrm{Ct}$ of each one of the triplicates was lower than 32 .

\section{Results and discussion}

Table 1 shows qPCR results of hair analysis (from back and flank) of wild rabbits from Valladolid province. The qPCR method was able to detect and quantify the presence of $L$. infantum kDNA in 4 out of 116 (3.5\%) analyzed animals. The estimated number of parasites in positive samples were quite variable, ranging from 2.60 to 276.60 . The highest quantity of parasite DNA was observed in the Z1 geographical area, being the estimated number of parasites in the hair of one individual (No. 15) up to 100 times greater than that observed in other animals. The results from animal No. 12 gave a Ct value (32.15) close to the threshold (32.00) but it was considered as negative. No positive results were found in animals from Z2, Z3, Zn or $Z s$ areas. The reliability of the results obtained was assessed by the $\mathrm{R}^{2}$ coefficient data (from 0.996 to 0.999 ), slope (from -3.36 to -3.33 ) and the high efficiency reached (between $98.56 \%$ and 99.64\%). Hair samples can be obtained by non-invasive methods in wild animals and they are stable to the environmental conditions of storage and transport $(7,12,13)$. Moreover, hair protects parasitic DNA from external degradation, storage at $-80^{\circ} \mathrm{C}$, desiccation and $\mathrm{UV}$ radiation (22). Our results demonstrate that hair is a proper sample for Leishmania detection in wild Leporidae.

The variability observed among animals regarding parasite load was in accordance with other studies previously published where scarce positive animals and low clinical impact were described $(11,23,24)$. Ortega et al. (23) studied the presence of $L$. infantum in leporids detecting for the first time $L$. infantum DNA in $67 \%(22 / 33)$ and $53 \%(17 / 32)$ of hair samples from rabbits and hares, respectively. These authors also found that the $100 \%(7 / 7)$ of rabbits and $33 \%(1 / 3)$ of hares were positive to the presence of $L$. infantum in all samples studied: spleen, skin and hair. This could be due to the fact that wild mammals would act as asymptomatic reservoirs since no macroscopic lesions were detected in post-mortem examination of positive animals (24). In the present study, no macroscopic lesions were found during the necropsy of the rabbits. Some authors $(21,25)$ reported that the absence of lesions could be due to (i) a recent association between the host and the parasite, (ii) to a low number of parasites or (iii) a reduced virulence of the parasite maximizing its transmission.

The knowledge of the ecology of leishmaniosis requires hard work to identify the hosts involved in
Tab. 1. Real Time PCR results of the analysis of hair (from back and flank). A positive PCR result was considered when the $\mathrm{Ct}$ mean (from triplicate analyses) was lower than 32 . No positive results were found animals from $\mathrm{Z2}, \mathrm{Z3}, \mathrm{Zn}$ or $\mathrm{Zs}$ areas. ND, not detected

\begin{tabular}{|c|c|c|c|c|c|}
\hline Area & $\begin{array}{l}\text { No. of } \\
\text { animals }\end{array}$ & $\begin{array}{c}\text { No. of } \\
\text { positives }\end{array}$ & Animal No. & Ct mean & $\begin{array}{l}\text { Mean of estimated } \\
\text { no. of parasites }\end{array}$ \\
\hline \multirow{13}{*}{$\mathbf{Z 1}$} & \multirow{13}{*}{19} & \multirow{13}{*}{4} & $1-4,8,10,14$ & ND & - \\
\hline & & & 5 & 36.75 & - \\
\hline & & & 6 & 31.14 & 2.60 \\
\hline & & & 7 & 37.68 & - \\
\hline & & & 9 & 39.78 & - \\
\hline & & & 11 & 38.40 & \\
\hline & & & 12 & 32.15 & - \\
\hline & & & 13 & 35.93 & - \\
\hline & & & 15 & 24.52 & 276.60 \\
\hline & & & 16 & 27.38 & 36.45 \\
\hline & & & 17 & 34.03 & - \\
\hline & & & 18 & 29.46 & 8.67 \\
\hline & & & 19 & 37.22 & - \\
\hline \multirow{7}{*}{ Z2 } & \multirow{7}{*}{28} & \multirow{7}{*}{0} & $3-13,15,18,20-28$ & ND & - \\
\hline & & & 1 & 35.61 & - \\
\hline & & & 2 & 38.95 & - \\
\hline & & & 14 & 38.76 & - \\
\hline & & & 16 & 38.72 & - \\
\hline & & & 17 & 36.91 & - \\
\hline & & & 19 & 36.88 & - \\
\hline \multirow{2}{*}{ Z3 } & \multirow{2}{*}{28} & \multirow{2}{*}{0} & $2-28$ & ND & - \\
\hline & & & 1 & 38.34 & - \\
\hline $\mathrm{Zn}$ & 22 & 0 & $1-22$ & ND & - \\
\hline Zs & 19 & 0 & $1-19$ & ND & - \\
\hline
\end{tabular}

the disease in different geographical areas. The studies involving wild mammals need costly techniques based on post mortem analysis or in vivo sampling (22). Xenodiagnostic studies already performed with wild rabbits and Iberian hares proved that these mammals are able to transmit $L$. infantum to $P$. perniciosus being strong evidence of its role in Leishmania transmission even those without clinical signs (20).

In Spain, L. infantum has been investigated in wild rabbits and hares in two geographical areas, i.e., Madrid $(2,11,18,23)$ and the southeastern Mediterranean coast (9). In the present study, the sampling area was close to a village with recently changed country areas that could promote the spreading of sand flies and rabbits.

Our results demonstrate that hair is a proper sample for Leishmania detection in wild Leporidae, as it has also been proven in other wild mammals. The results of the present study show the important role of wild Leporidae - rabbits in the present work - as reservoirs of Leishmania, leading to the need for more extensive studies together with an entomological survey to elucidate the possible role of wild rabbits in a sylvatic cycle of transmission of $L$. infantum in this area. 


\section{References}

1. Alvar J., Vélez I. D., Bern C., Herrero M., Desjeux P., Cano J., Jannin J., Boer M. den: Leishmaniasis worldwide and global estimates of its incidence. PLoS One 2012, 7, e35671.

2. Arce A., Estirado A., Ordobas M., Sevilla S., García N., Moratilla L., de la Fuente S., Martinez A. M., Pérez A. M., Aránguez E., Iriso A., Sevillano O., Bernal J., Vilas F.: Re-emergence of leishmaniasis in Spain: community outbreak in Madrid, Spain 2009 to 2012. Eurosurveillance 2013, 18, 1-9.

3. Ashford R.: The leishmaniases as emerging and reemerging zoonoses. Int. J. Parasitol. 2000, 30, 1269-1281.

4. Ashford R. W.: Leishmaniasis reservoirs and their significance in control. Clin. Dermatol. 1996, 14, 523-532.

5. Belinchón-Lorenzo S., Iniesta V., Parejo J. C., Fernández-Cotrina J., MuñozMadrid R., Soto M., Alonso C., Gómez-Nieto L. C.: Detection of Leishmania infantum kinetoplast minicircle DNA by Real Time PCR in hair of dogs with leishmaniosis. Vet. Parasitol. 2013, 192, 43-50.

6. Belinchón-Lorenzo S., Parejo J. C., Iniesta V., Fernández-Cotrina J., MuñozMadrid R., Monroy I., Baz V., Gómez-Luque A., Serrano-Aguilera F. J., Barneto J. L., Gómez-Nieto L. C.: First detection of Leishmania kDNA in canine cerumen samples by qPCR. Vet. Parasitol. 2016, 228, 65-68.

7. Bengtsson C. F., Olsen M. E., Brandt L. Ø., Bertelsen M. F., Willerslev E., Tobin D. J., Wilson A. S., Gilbert M. T. P.: DNA from keratinous tissue. Part I: Hair and nail. Ann. Anat. - Anat. Anzeiger 2012, 194, 17-25.

8. Burza S., Croft S. L., Boelaert M.: Leishmaniasis. Lancet 2018, 392, 951-970.

9. Chitimia L., Muñoz-García C. I., Sánchez-Velasco D., Lizana V., del Río L., Murcia L., Fisa R., Riera C., Giménez-Font P., Jiménez-Montalbán P., Martínez-Ramírez A., Meseguer-Meseguer J. M., García-Macete I., SánchezIsarría M. A., Sanchis-Mosonís G., García-Martínez J. D., Vicente V. Segovia M., Berriatua E.: Cryptic Leishmaniosis by Leishmania infantum, a feature of canines only? A study of natural infection in wild rabbits, humans and dogs in southeastern Spain. Vet. Parasitol. 2011, 181, 12-16.

10. Cowan D. P.: The use of ferrets (Mustela furo) in the study and management of the European wild rabbit (Oryctolagus cuniculus). J. Zool. 1984, 204, 570-574 .

11. García N., Moreno I., Alvarez J., de la Cruz M. L., Navarro A., PérezSancho M., García-Seco T., Rodríguez-Bertos A., Conty M. L., Toraño A., Prieto A., Dominguez L., Dominguez M.: Evidence of Leishmania infantum Infection in Rabbits (Oryctolagus cuniculus) in a Natural Area in Madrid, Spain. Biomed Res. Int. 2014, 2014, 1-5.

12. Garzel L. M., Hankenson F. C., Combs J., Hankenson K. D.: Use of quantitative polymerase chain reaction analysis to compare quantity and stability of isolated murine DNA. Lab. Anim. (NY) 2010, 39, 283-289.

13. Gilbert M. T. P., Menez L., Janaway R. C., Tobin D. J., Cooper A., Wilson A. $S$.: Resistance of degraded hair shafts to contaminant DNA. Forensic Sci. Int. 2006, 156, 208-212.

14. González E., Jiménez M., Hernández S., Martín-Martín I., Molina R. Phlebotomine sand fly survey in the focus of leishmaniasis in Madrid, Spain (2012-2014): seasonal dynamics, Leishmania infantum infection rates and blood meal preferences. Parasit. Vectors 2017, 10, 368

15. González E., Molina R., Iriso A., Ruiz S., Aldea I., Tello A., Fernández D., Jiménez M.: Opportunistic feeding behaviour and Leishmania infantum detection in Phlebotomus perniciosus females collected in the human leishmaniasis focus of Madrid, Spain (2012-2018). PLoS Negl. Trop. Dis. 2021, 15, $\mathrm{e} 0009240$.

16. Iniesta V., Belinchón-Lorenzo S., Soto M., Fernández-Cotrina J., MuñozMadrid R., Monroy I., Baz V., Gómez-Luque A., Parejo J. C., Alonso C., Nieto L. C. G.: Detection and chronology of parasitic kinetoplast DNA presence in hair of experimental Leishmania major infected BALB/c mice by Real Time PCR. Acta Trop. 2013, 128, 468-472.

17. Jiménez M., González E., Iriso A., Marco E., Alegret A., Fúster F., Molina R. Detection of Leishmania infantum and identification of blood meals in Phlebotomus perniciosus from a focus of human leishmaniasis in Madrid, Spain. Parasitol. Res. 2013, 112, 2453-2459.

18. Jiménez M., González E., Martín-Martín I., Hernández S., Molina R.: Could wild rabbits (Oryctolagus cuniculus) be reservoirs for Leishmania infantum in the focus of Madrid, Spain? Vet. Parasitol. 2014, 202, 296-300.

19. Martínez B. F., Barroso D. G., Portero C.: La Leishmaniasis en España: Evolución de los casos notificados a la Red Nacional de Vigilancia Epidemiológica desde 2005 a 2017 y resultados de la vigilancia de 2014 a 2017. Boletín Epidemiológico Sem. 2019, 27, 15-27.
20. Molina R., Jiménez M. I., Cruz I., Iriso A., Martín-Martín I., Sevillano O., Melero S., Bernal J.: The hare (Lepus granatensis) as potential sylvatic reservoir of Leishmania infantum in Spain. Vet. Parasitol. 2012, 190, 268-271.

21. Moreno I., Álvarez J., García N., de la Fuente S., Martínez I., Marino E., Toraño A., Goyache J., Vilas F., Domínguez L., Domínguez M.: Detection of anti-Leishmania infantum antibodies in sylvatic lagomorphs from an epidemic area of Madrid using the indirect immunofluorescence antibody test. Vet. Parasitol. 2014, 199, 264-267.

22. Muñoz-Madrid R., Belinchón-Lorenzo S., Iniesta V., Fernández-Cotrina J., Parejo J. C., Serrano F. J., Monroy I., Baz V., Gómez-Luque A., Gómez-Nieto L. C.: First detection of Leishmania infantum kinetoplast DNA in hair of wild mammals: Application of qPCR method to determine potential parasite reservoirs. Acta Trop. 2013, 128, 706-709.

23. Ortega M. V., Moreno I., Domínguez M., de la Cruz M. L., Martín A. B., Rodríguez-Bertos A., López R., Navarro A., González S., Mazariegos M., Goyache J., Domínguez L., García N.: Application of a specific quantitative real-time PCR (qPCR) to identify Leishmania infantum DNA in spleen, skin and hair samples of wild Leporidae. Vet. Parasitol. 2017, 243, 92-99.

24. Ortega-García M. V., Salguero F. J., Rodríguez-Bertos A., Moreno I., García N., García-Seco T., Luz Torre G., Domínguez L., Domínguez M.: A pathological study of Leishmania infantum natural infection in European rabbits (Oryctolagus cuniculus) and Iberian hares (Lepus granatensis). Transbound. Emerg. Dis. 2019, 66, 2474-2481.

25. Quinnell R. J., Courtenay O.: Transmission, reservoir hosts and control of zoonotic visceral leishmaniasis. Parasitology 2009, 136, 1915-1934.

26. Ruiz-Postigo J. A., Grout L., Jain S.: Global leishmaniasis surveillance, $2017-$ -2018 , and first report on 5 additional indicators. Wkly. Epidemiol. Rec. WHO 2020, 95, 265-280

27. WHO: Control of the leishmaniases. World Health Organ. Tech. Rep. Ser. 2010 .

Corresponding author: Emiliano J. Quinto, Area of Nutrition and Food Science, Faculty of Medicine, University of Valladolid, Spain; e-mail: equinto@uva.es 